\title{
O MUSEU DE CIÊNCIA: ESPAÇO DA HISTÓRIA DA CIÊNCIA
}

\section{The Science Museum: a place of history of science}

\author{
Maria Esther Alvarez Valente*
}

\begin{abstract}
Resumo: O artigo apresenta uma reflexão sobre o Museu de Ciência a partir de sua dimensão educativa. O que está em discussão é a abordagem sobre os temas científicos e a exploração dos objetos museológicos apresentados no sentido de facilitar o entendimento público da Ciência. Principalmente a partir da segunda metada do século XX, a comunicação nestes espaços, voltada para o público leigo, opta por estratégias que priorizam, quase exclusivamente, a apresentação de fenômenos científicos, construindo desta maneira saberes a-históricos. Com base na perspectiva da História da Ciência o esforço, hoje, é o de ampliar a interpretação dos temas e objetos, revelando a intangibilidade ligada a eles, e que compreendem o ato de criação científico, os processos de conhecimento da ciência e sua relação com o homem e a sociedade. Trata-se de uma abordagem que auxilia os indivíduos a dar significado aos conteúdos científicos.
\end{abstract}

Unitermos: educação em museus de ciência, educação não formal, educação e história da ciência

Abstract: The article is bringsa reflection on the science museum focusinged on its educational dimension. The discussion is about the approach of the interpretation ofn scientific themes and objects, both presented in the museum's exhibitions, in order to promote the public's understanding of science. Starting mainly in the second half of the twentieth century, communication occurred in Science Museums and more precisely in Science Centres, with presentations focused, exclusively on the scientific phenomena. What results is a knowledge without historical foundations. Instead we propose another approach based on the history of science perspective. It opens up the interpretation ofn the intangible aspectsside of the objects as well asand the cold information. It emphasisesis the act of scientificce creation, the process of science knowledge and its relationship with man and society. The new approach will help people give significance to the scientific contents.

Keywords: education in science museum, non formal education, education and history of science

\section{Introdução}

O presente artigo está inserido no âmbito dos Museus de Ciência. Trata da discussão sobre as possibilidades de articulações entre os objetos de valor histórico e as questóes da ciência, apontando a perspectiva da História da Ciência como estratégia usada para alcançar uma comunicação eficiente na ampliação da cultura científica da sociedade.

A fim de oferecer uma melhor compreensão do desenvolvimento da reflexão, cabe esclarecer que, ao analisar questóes ligadas ao Museu de Ciência e de sua apresentação para o público, parte-se do princípio que o museu, como comunicador, se move por meio da expansão de sua Dimensão Educativa. A abordagem se faz destacando três momentos. Inicia-se pelo ambiente no qual se tem implementado os museus de ciência e tecnologia. Neste contexto, são apresentados aspectos sobre os museus, seus objetos e a História da Ciência como perspectiva. Ao final, uma experiência abre a discussão relativa à utilização dos objetos históricos do Museu de Ciência para além de sua conservação e apresentação estática, ampliada para a tendência que trata de sua intangibilidade.

\footnotetext{
* Coordenação de Educação do Museu de Astronomia e Ciências Afins - Mast. Mestre em Educação PUC/Rio. Doutoranda do Programa em Ensino e História de Ciências da Terra do IGE/Unicamp. E-mail: esther.trp@terra.com.br 


\section{O Ambiente}

A educação tem sido destacada como recurso de indiscutível importância para enfrentar os novos desafios gerados pela globalização e pelo avanço tecnológico na era da informação. Para tal, o conceito de educação, voltado durante muito tempo prioritariamente para os processos de ensino-aprendizagem, exclusivo das unidades escolares formais, tende a se ampliar. E, assim, transpõe os muros da escola se alargando para os espaços da casa, do trabalho, do lazer etc. Com isso, um novo campo da educação se estrutura: o da educação não formal (Gohn, 1999). Hoje, vários espaços contribuem para o mesmo fim educativo que tem como meta suprir a sociedade em suas carências de conhecimento. Neste contexto, os museus são eleitos como fontes importantes de aprendizagem e podem contribuir para o enriquecimento cultural científico dos indivíduos: os que estão na escola, aqueles que não tiveram esta oportunidade e os que já estão fora dela.

As questôes manifestadas na sociedade, que abrigam os movimentos sociais que reivindicavam direitos políticos, econômicos, sociais, culturais e a construção da cidadania pela educação, também alteram o papel da instituição que tem como função comunicar e socializar o conhecimento. Portanto, hoje, os museus de ciência, em sua atuação, devem ter em maior conta as implicaçóes do atual contexto social. Um novo momento surge para os museus de ciência e tecnologia. Estes tomam um tal impulso que um fenômeno de proliferação de instituiçôes é percebido no mundo todo. Os museus multiplicaram-se como resposta a uma demanda e como recurso para a melhoria da relação dos indivíduos com a C\&T. Nesse movimento surge outra modalidade de museu de ciência o denominado Science Center (Centro de Ciência).

Ampliando sua dimensão educativa, os museus, como espaços de preservação e guardiōes do passado, aproximam-se dos aspectos da ciência contemporânea e também contemplam a visão de que a historicidade é característica relevante para se pensar cientificamente, ou seja, o universo é sujeito de transformação permanente e portanto, tem uma história. Nesta ótica os museus têm perseguido a associação dos fenômenos naturais com a história. Por meio dela é permitido o entendimento do processo dos eventos. Esta versão visa aproximar o homem leigo do conhecimento preservado e apresentado no museu. Se o século XX inicia com a mistificação da ciência, no fim do século a tendência pedagógica é a desmistificação.

Durante a década de 1980, com base em princípios democráticos e respeito aos direitos humanos, um número considerável de países e a Organização das Nações Unidas para a Educação, Ciência e Cultura (Unesco) assumiram um compromisso internacional no que diz respeito à Educação em Ciências disseminando a idéia de "ciência para todos" e ao longo da vida. A educação científica não será exclusiva das escolas e para os estudantes enquanto futuros cidadãos. Como afirma Fensham (1999), o conhecimento que o público adulto tem sobre os temas científicos mais atuais e relevantes, não vem das experiências escolares, mas da ação da divulgação científica da mídia eletrônica de qualidade e dos museus de ciência, que trazem para as suas exposiçóes, tanto os conhecimentos científicos/tecnológicos clássicos, quanto as temáticas atuais e/ou polêmicas. Neste sentido, os novos museus e centros de ciência têm se preocupado em dar acesso a todos convidando o público leigo a participar. Esses são alguns dos aspectos que orientam as formas de conceber os novos espaços.

\section{Buscando um caminho - Uma perspectiva para o museu de ciências}

Os museus de ciências, particularmente europeus e norte-americanos, a partir da segunda metade do século XX, no esforço de se aproximarem do público passaram a adotar 
estratégias inovadoras representadas, muitas vezes, pela substituição dos objetos históricos por aparatos didáticos para demonstrar fenômenos científicos. Pretendia-se aproximar o leigo da ciência por meio de um tipo de interação que tinha no manuseio dos aparatos o principal apelo. Como conseqüência diluiu-se os aspectos culturais e históricos dos objetos tradicionais e massificou-se um modelo que foi disseminado pelo mundo. A eficácia das diversas formas de facilitar, nos museus, o entendimento público da ciência, provocou debates que levantaram muitas questões e que vão desde as diferentes maneiras de apresentar a ciência até sua relação com a sociedade.

Observa-se que enquanto os museus de ciência e técnica tradicionais, que apresentam o saber de forma linear, mostram dificuldade em comunicar uma perspectiva compreensiva do conhecimento científico atual, os centros de ciência apresentam a ciência sem antecedentes, fora do contexto cultural e fragmentada. Percebe-se, entretanto, que o conhecimento veiculado em ambos seria melhor aproveitado se as duas versões combinassem seus aspectos positivos em um conjunto museológico coerente (Bragança Gil, 1988). Os dois poderiam evidenciar as mudanças do pensamento científico e tecnológico como produto das transformações nas relaçôes humanas contemporâneas e passadas se os centros de ciência se preocupassem, também, pelo passado e os museus de ciência e técnica estivessem interessados na ciência e na tecnologia contemporâneas.

$\mathrm{Na}$ ampliação dessas temáticas o museu considera, ainda, outra questão que está para além da materialidade dos objetos. Como passar dos princípios da conservação e da exposição de traços materiais (espécies naturalizadas, fósseis, instrumentos, obras etc.) para os da apresentação de processos naturais, culturais, técnicos etc., que têm origem no intangível. Tal questão implica em incorporar, também na esfera dos museus de ciência e técnica, ao lado do patrimônio tradicional material, o patrimônio intangível (Valente e Marandino, 2003).

O patrimônio intangível está ligado aos aspectos relativos à conservação dos processos e fenômenos, incluindo o cultural e o natural, e compreende todos os atos de criação, inclusive o da Ciência. Neste sentido, segundo Van-Präet (2002) a museologia contemporânea das ciências e das técnicas não pode fazer abstração da reflexão e das investigaçôes sobre este patrimônio. Para ele, o sucesso de uma exposição acontece, sobretudo, quando ocorre a operacionalização de uma trama de concepçóes em que o desenvolvimento dos conteúdos e da forma combina vários procedimentos. Assim como a entrada do patrimônio intangível reestruturou profundamente a instituição museu, transformando os museus de ciências e levando amplamente à criação dos centros de ciências, que privilegiam a apresentação de fenômenos naturais, é fundamental, hoje, ultrapassar as formas atuais de mediação para responder aos desafios da comunicação. O mesmo autor indica algumas vias alternativas para o desenvolvimento de exposiçōes. Tais alternativas implicam em mostrar ao público que visita os museus: i) que o patrimônio da criação científica é mais vasto do que o que está exposto nos museus; ii) que o patrimônio natural não está submetido apenas às interações visíveis aqui e agora. Todo patrimônio é uma construção humana e, portanto, são do domínio do intangível. Essa perspectiva valoriza a idéia de que o objeto de museu e a exposição são construçôes sociais.

Procurando articular os diferentes aspectos aqui levantados, cabe acrescentar que os museus têm laços estreitos com a sociedade e são veículos de suas representações e, sendo assim, o museu em sua dimensão comunicativa e educativa não pode descuidar de sua relação com o público. As demandas atuais da sociedade supõem a restruturação do museu adaptando as novas idéias à antiga instituição e, ao mesmo tempo, sem desprezar o seu potencial histórico. Portanto, hoje a tendência está em produzir um equilíbrio entre o interesse pelos objetos históricos e um interesse pelo que a sociedade reclama. Como diz Eilean Hooper-Greenhill (1998) "os velhos 
princípios de conservação devem agora compartilhar seu papel predominante com o novo conceito de negociação". ${ }^{I} \mathrm{O}$ ato de colecionar, como fim em si, não é mais suficiente, ao contrário, deve ser visto como meio de aproximação das pessoas e de seus interesses.

O compromisso do museu é o de ajudar na construção de uma sociedade capaz de fazer face ao presente e ao futuro, ampliando a confiança no conhecimento e na compreensão do ambiente em que se vive, considerando a história e a cultura de diferentes lugares e indivíduos, tomando, assim, a diversidade no seu interior e transformando a diferença em vivência positiva.

No museu dedicado à ciência e à tecnologia, a perspectiva que se mantém como desafio, é a de evitar a elaboração de apresentaçôes que levam à separação entre as disciplinas das ciências sociais e naturais, procurando, ao contrário, contemplar a ligação com as áreas da Filosofia da Ciência e da História da Ciência. Na Educação em Ciência, e face ao analfabetismo científico, esta aproximação é oportuna. A História, a Filosofia e a Sociologia da Ciência, no quadro de dificuldades de acesso ao entendimento da ciência, aproximam os interesses éticos, culturais e políticos dos indivíduos, tornam seus assuntos mais estimulantes, reflexivos e incrementam as capacidades do pensamento crítico.

No campo da Educação em Ciência fundamenta-se essa contribuição, recorrendo a Matthews (1994), que ao tratar do ensino, valoriza a tradição contextualizada à História da Ciência como forma de favorecer positivamente o ensino de ciências, uma vez que, nesta perspectiva, o conteúdo é humanizado, facilitando a compreensão dos conceitos científicos apresentados. Segundo ele há um valor intrínseco para o entendimento da ciência que pode depender da compreensão dos episódios crucias na História da Ciência. A apresentação da ciência pelo processo histórico mostra que a ciência é mutável e que se transforma. Conseqüentemente o conhecimento científico atual é suscetível de se transformar. A História da Ciência na visão de Pedrinaci (1994), facilita entender o processo do conhecimento científico na medida em que apresenta "como surgem as teorias, como a comunidade científica oferece resistência ao desligar-se do paradigma vigente até esse momento, como tem um período de aceitação mais ou menos longo e como, finalmente, são superadas por outras idéias com maior poder explicativo". ${ }^{2}$ Para ele, provavelmente, ela é o melhor antídoto contra uma visão dogmática da ciência como verdade absoluta e definitiva.

A História da Ciência, focalizada nesta direção, permite um conhecimento mais rico do método científico, uma vez que pode mostrar as pautas de mudança da metodologia consensual, rompendo-se com o mito do único e infalível método científico. $\mathrm{O}$ museu, ao se apropriar dessas abordagens contribui, também, para a compreensão dos conteúdos científicos apresentados em suas exposiçōes e explorados em seus objetos.

Assim concebida, a História da Ciência representa um meio para solucionar a questão da barreira artificial entre os diferentes estudos científicos, uma vez que se articula no sentido de procurar eliminar os preconceitos, as idéias cristalizadas e significados arraigados ao saber científico, e que bloqueiam qualquer tentativa de aproximação. Para compreender uma concepção teórica é necessário entender seu desenvolvimento histórico. Busca-se, em última instância, não o conhecimento de resultados isolados, como um conjunto de conteúdos sistematizados, mas do entendimento do processo que é um conhecimento necessariamente histórico.

Cabe ressaltar que, nas apresentações, essa história não representa apenas a inclusão de fatos históricos e de Filosofia da Ciência, mas na articulação das diferentes disciplinas e interaçãoo de diferentes caminhos. A inclusão da temática sobre a "natureza da ciência", de forma mais completa, mais rica, auxilia na melhor compreensão dos assuntos relativos à ciência. Ela aprimora o

${ }^{1}$ HOOPER-GREENHILL, EILEAN, (1998). Los Museos y sus visitantes. Espanha: Ediciones Trea. p. 13

${ }_{2}^{2}$ Pedrinaci, E. (1994). La história de la geología como herramenta didática. Enseñanza de las Ciencias de la Tierra. p. 337 
conhecimento sobre a compreensão das formas de como mudam as idéias científicas no tempo e como a natureza destas idéias e os usos a que se aplicam são afetados pelos contextos social e cultural em que se desenvolvem.

Formados neste cenário espera-se, realmente, que os indivíduos captem algo dos aspectos intelectuais que estão em jogo nos temas científicos e percebam que existem perguntas a fazer e ainda, que comecem a pensar não só nas respostas, se não também sobre o que se poderia considerar como resposta e que tipo de evidências podem corresponder às respostas. Desta forma acredita-se que a ciência relacionada à sua dimensão cultural e filosófica pode desenvolver habilidades para um pensamento crítico.

Programas para a introdução da História da Ciência na Educação em Ciência têm sido incorporados pela educação formal e mesmo em instituições voltadas para a educação não formal. Essa mudança pode significar implicações na formação de todos. O museu como uma instância educativa tem se mostrado favorável aos programas e procura atuar por meio de açóes que incorporam as questóes de articulação entre ciência, tecnologia e sociedade. Trata-se pois, de adotar uma versão contextualizada das ciências que apresente a ciência em seu meio social, histórico, filosófico, ético e tecnológico.

A diferença entre ser educado em ciências e simplesmente ser formado em ciências é possuir o conhecimento da dimensão cultural e histórica da própria disciplina. A história da Filosofia da Ciência contribui claramente para a rica compreensão da ciência. Quanto a isto, na opinião de Miller (1983), se estar alfabetizado cientificamente é compreender com certa profundidade as palavras e conceitos de um discurso, então, a História e a Filosofia da Ciência contribuem amplamente para uma alfabetização científica mais profunda e crítica. A ciência é uma das grandes realizaçóes da cultura humana. Assim, para se conseguir vencer a presente crise social e intelectual da Educação em Ciências deveria se transmitir mais o espírito desse logro.

É fundamental a mudança da antiga concepção de museu como lugar de guarda de coleções. O museu instituição de preservação das produções da natureza e do espírito humano é também local de comunicação cultural ampliando sua atuação sobre os registros do saber e da fruição. A preservação não é passiva e pode ser desmistificadora considerando os indivíduos envolvidos nas tramas dos processos da construção da ciência e da tecnologia. Isto dá ao museu um caráter transformador.

A ciência mudou drasticamente a visão de mundo, e o papel do historiador torna-se muito mais complexo que compilar fatos ou dedicar-se à exclusiva memória de personagens. Cada geração reescreve a história do mundo à luz de novas idéias e conhecimentos estabelecidos em cada época. A percepção desta transformação permite, pois, o estabelecimento de ligações entre concepções do passado e do presente, reduzindo o vazio entre momentos históricos e acrescentando mudanças culturais.

O desafio atual é, portanto, realizar exposições que ao abordar temáticas científicas e em situações em que se apresentem instrumentos científicos, considerem diversos aspectos de ordem histórica e metodológica, como por exemplo: evidências das condições culturais nas quais o instrumento científico foi elaborado, e que objetivem ajudar, o visitante do museu, a entender os aspectos culturais e históricos relacionados a eles; a discussão sobre ciência como conhecimento e atividade; a tensão entre ciência e técnica; a mudança da perspectiva de uma abordagem linear para uma abordagem sociocultural; a própria questão da aproximação interativa por meio de aparatos manipuláveis na comunicação da ciência para novas audiências; a relação que se estabelece entre o visitante do museu e o objeto e os modelos científicos em uma exposição.

A exploração de temas científicos por meio da apresentação do processo histórico, ligado com os aspectos culturais e sociais, ajuda a ver a ciência como uma construção humana 
coletiva. Contribui para o entendimento do caráter hipotético do ensaio e erro da pesquisa. Auxilia, também, o visitante do museu a compreender que o conhecimento é alcançado depois de superados os preconceitos e obstáculos, por meio de uma longa e densa discussão, em tempos e lugares determinados e contribui para o melhor conhecimento da estrutura da ciência.

Os instrumentos científicos tangíveis expostos no museu, explorados a partir dessa abordagem, facilitam a introdução da relação entre a ciência e a técnica levando os indivíduos a darem significado aos conteúdos científicos. Estes, articulados à diferentes temas e disciplinas - Astronomia, Geografia, História, aspectos cultuais, técnicas -, facilitam a motivação dos indivíduos para a compreensão das temáticas científicas. Além de criar a oportunidade para que as pessoas, por meio da introdução de aspectos significativos, possam interpretar os fatos e compreender a significação dos mesmos. Procura-se, assim, superar o mar de coisas sem sentido para o visitante, que de forma geral vê os cientistas como personagens encarcerados em laboratórios recitando fórmulas e equaçōes que poucos compreendem.

\section{A experiência no museu: uma reflexão sobre a prática}

Com o foco sobre os museus de ciência e em sua dimensão educativa, e a partir da aproximação com o que diz Amorim (1998), pode-se constatar o quadro que em geral é apresentado para dar acesso ao saber. "Na atualidade, a educação científica, tanto escolar quanto não escolar, tem sido bastante questionada, particularmente no que diz respeito às reais possibilidades que conferem à participação consciente e crítica dos cidadãos na nossa sociedade, altamente tecnológica e cientificizada. A educação científica, tal como se apresenta, prioriza o conteúdo científico, ou seja, o produto de uma construção humana e histórica, geralmente apresentado de uma forma neutra e a-histórica. Além disso, esse produto vem sendo cada vez mais sintetizado sob a forma dos conceitos científicos aos quais, na maioria dos casos, a população tem acesso sob forma de uma linguagem extremamente técnica, se não incompreensível, ou a partir de simplificaçōes reducionistas e errôneas". ${ }^{3}$

Esta preocupação é uma das questōes que norteiam as experiências voltadas à relação museu-escola desenvolvidas pela Coordenação de Educação em Ciência do Museu de Astronomia e Ciências Afins - MAST e que, entre outros interesses, procura conhecer como os professores se apropriaram dos elementos que caracterizam a especificidade da instituição e como são incorporados na prática pedagógica durante a visita ao museu. Uma dessas experiências é a oficina Aprendendo com os objetos.

A atividade tem por propósito explorar a função significativa dos objetos do museu para a ampliação do conhecimento. A iniciativa reporta-se a diversas situaçóes em que o professor, visitando a instituição, manifesta dificuldades para explorar o potencial educativo dos objetos do museu - instrumentos científicos históricos - com os alunos. Para tal procura-se, por meio da oficina, auxiliar o professor na forma de olhar os objetos museológicos. Acredita-se que a substituição do olhar passivo por um olhar questionador leva não só à aquisiçãao de conhecimento como ao refinamento da visão de mundo daqueles envolvidos na atividade.

A literatura ${ }^{4}$, relativa ao objeto na educação em museus, mostra que a observação investigativa sobre uma peça pode destacar mais que aspectos externos da coisa em questão.

\footnotetext{
${ }^{3}$ Amorim, Antonio Carlos Rodrigues de. (1998) Relaçôes entre ciêncialtecnologialsociedade na formação de professores: contribuiçôes da história e sociologia da ciência. Física y cultura: cuadernos sobre historia y enseñanza de las ciencias. v. 6, n. 1 , outubro.

${ }^{4}$ Entre outros: GILBERT, JOHN. (1995) Learning in Luseums: objects, models and text. Journal of Education in Museums, 16 e DURBIN, G. MORRIS, S. WILKINSON, S. (1990). A Theacher's Guide to Learning from Objects. London English Heritage.
} 
Quando relacionada aos indivíduos e referida a uma época, indica maneiras de pensar e identifica necessidades, concepções, valores, mudanças e diferenças. Ao caracterizar seu funcionamento, permite superar as formas físicas e materiais usados na confecção do objeto, evidenciando usos e produção. Ao aproximá-lo do presente ou do futuro, atualizando-o, pode-se mesmo arriscar previsōes. A dinâmica para entender os objetos leva, também, à articulação de várias áreas do saber e favorece o aperfeiçoamento de maneiras de aprender: observar e classificar elementos; comparar informações e opiniōes; predizer idéias; testar hipóteses e suposições; registrar, avaliar e interpretar dados e concepções. E ainda, ao valorizar a experiência, os sujeitos envolvidos no exercício otimizam a habilidade de inquirir, de argumentar e de construir suas próprias explicações dando sentido ao que vêem.

O encaminhamento da atividade é baseado na perspectiva construtivista, a articulação sujeito/objeto, por meio de um processo de interação, é constante e contínua e se distingue pelo deslocamento sucessivo de um e de outro: ora o sujeito determina ao objeto uma propriedade, ora este a impóe - constrói-se desta maneira uma explicação (Salvador, C.,1994). Ao mesmo tempo, a exploração dessa relação tem um caráter investigativo conduzido do ponto de vista da história da ciência. A relação sujeito/objeto, entendida como ação dinâmica, é mediada pelo profissional do museu com o professor, de forma que na interação com o objeto museal, sejam criadas simultaneamente habilidades para aprender (Hein, G.,1995). Procura-se por meio de uma ação questionadora possibilitar o engajamento intelectual do professor em uma experiência museal. A orientação é focada na interrogação - estratégia de explorar o objeto do museu de forma que conduza à informação, ao conhecimento e auxilie na localização, identificação e interpretação das características significativas do objeto.

Inicialmente, o professor é colocado frente ao instrumento científico que será abordado, sem que a ele seja dado qualquer tipo de informação. Apenas é orientado a expressar o que vê. Em um primeiro momento a falta de familiaridade do professor com o objeto apresentado gera uma relação de expectativa. Inicia-se a exploração do objeto por meio de perguntas observacionais cujas respostas dizem respeito ao que está visível.

A percepção do professor em relação ao objeto favorece, então, a conexão com a estrutura de pensamento. A partir daí, ele é encorajado à reflexão. Impulsiona-se, desta maneira, o professor a promover relações, partindo da observação sobre o objeto, articulando as primeiras percepções com as possíveis temáticas que surgem e suas concepções prévias sobre o que vê. Daí em diante as perguntas e respostas vão se tornando mais complexas e abrangentes à medida que as informações e idéias levantadas ampliam a conversação. Ao interpretar as evidências, mobilizado pelas pistas fornecidas (referentes ao passado e temas destacados), o professor faz julgamentos e reelabora seus argumentos promovendo um ajuste dos aspectos descritivos (cor, tamanho, material) com aqueles mais intrínsecos e intangíveis (propósitos, necessidades, valores, comportamentos, procedimentos), formulando idéias em um contexto mais amplo. Confrontando as informações obtidas na reflexão, comparando o antigo com o novo e contrastando técnicas para entender as mudanças nos objetos e os efeitos destes na vida das pessoas, mantém-se uma discussão viva em que o professor elabora suas próprias idéias.

É o questionamento constante do real que nos concede o conhecimento das coisas e o olhar atento de investigador que permite desvendar de um objeto museológico não só seu funcionamento, mas o uso e os sujeitos nele envolvidos e que fornece sentido ao que se vê. A posição que toma o sujeito de uma ação que interage a partir de uma nova sensibilidade com o mundo é de um olhar diferenciado, que vê nas entrelinhas detalhes e evidências, em suma, que vai mais fundo, desvendando circunstâncias, superando uma visão de contemplação passiva. 
A meta de educar para transformar está estritamente marcada na mudança de atitude sensível do sujeito, situada no âmbito histórico dos homens e compreendida em uma atitude de vida. No projeto de vida as circunstâncias não se limitam às facilidades que possibilitam a existência, mas também agregam o conjunto de dificuldades que surgem no seu desenrolar. Além disto, o entorno onde se processa não é constituído apenas de minerais, vegetais, animais e do homem, mas ainda do conjunto dos usos e maneiras de pensar que formam o mundo social e que o humanizam. Nos museus de ciência e técnica, freqüentemente, o que é apresentado parece, aos olhos do visitante, paradoxalmente abstrato, porque não se identificam com o que vêem. Neles, a História da Ciência pode ajudar a construir uma imagem mais compreensiva da ciência e dos cientistas.

A experiência com o objeto é um trabalho indutivo mas que está intimamente ligado a uma perspectiva histórica, e nos museus de ciência, essa abordagem da História da Ciência, deve ser o enfoque privilegiado. As informações a serem transmitidas não devem, pois, ser selecionadas com base apenas nos resultados da ciência ou em função, somente, das possíveis necessidades sociais. Conforme diz Gangliardi e Giordan (1986), não se trata de oscilar entre informação teórica e as receitas teóricas, o que importa está em transmitir saberes que facilitem o desenvolvimento da capacidade de aprender e de utilizar o que é aprendido.

Trata-se de uma experiência cuja proposta reconhece a função pedagógica do museu e possibilita a ampliação do conhecimento ao explorar seus instrumentos científicos. Com essa atitude os profissionais envolvidos na atividade ultrapassam os limites dos elementos visíveis que compõem o instrumento científico trabalhado. O exercício parte da concepção de objeto de museu visto em uma perspectiva que privilegia o como os indivíduos pensam e pensavam sua inserção na sociedade e como viveram determinadas experiências históricas, rejeitando-se, dessa maneira, a visão do objeto enquanto relíquia e raridade que comporta uma visão incompleta e por vezes deturpada da realidade.

Ao analisar essas observações pode-se dizer, como Gangliardi e Giordan (1986), que as discussões da educação em ciência, com base na história da ciência, podem ser, ao mesmo tempo, uma discussão sobre o que é conhecer e como se conhece. "Ao mostrar que cada conhecimento atual é o resultado de um longo processo, que não basta algumas experiências para mudar uma teoria, que os fatores sociais têm muito peso, podemos começar a desmistificar a imagem da ciência na população". 5

Cabe dizer que aprender a entender os objetos facilita dar sentido ao mundo: deduzindo onde os objetos são feitos, como funcionam, desvendando os agentes sociais neles envolvidos (na idealização, confecção, utilização), descobrindo quando foi produzido, revelando as necessidades e dificuldades em sua realização e os motivos de sua confecção, confrontando-os com outros grupos sociais de diferentes culturas, reconhecendo influências e possíveis embates, que provocam mudanças de valores, conhecendo e respeitando as semelhanças e diferenças deles abstraídas. Introduzindo, desta forma, assuntos relacionados a como se organiza a produção do conhecimento, dos impactos que a introdução de nova instrumentação causa na própria teoria e métodos científicos, na classificação e descrição do mundo. Além disso, convidam à compreensão dos debates da ciência, dos métodos disponíveis em determinada época, das dúvidas, dos avanços, e retrocessos na precisão dos instrumentos, a função social da ciência e ainda dos assuntos relacionados ao cotidiano. A oficina proposta permite aos profissionais - de museus e professores - uma reflexão que transcende o objeto em si mesmo, entendendo-o como mediador de experiências de diferentes grupos sociais em tempos-espaços também diferentes.

\footnotetext{
${ }^{5}$ Gangliardi, R. e Giordan, A. (1986) La Historia de Las Ciencias: una herramienta para la enseñanza. Enseñanza de las ciencias, $v .4, n .3$, p. 254
} 
A tendência fundamental operada no museu é a de que o antigo lugar privilegiado do objeto museológico é tomado por sua relação com o homem. O tangível aliado ao intangível faz com que a instituição esteja continuamente adaptada aos meios social e cultural, valorizando os processos dinâmicos das relações entre o ser humano e a natureza, entre a sociedade, a ciência e a tecnologia.

\section{Referências}

AMORIM, A. C. R. de. Relações entre ciência/tecnologia/sociedade na formação de professores: contribuições da história e sociologia da ciência. Física y cultura: cuadernos sobre historia y enseñanza de las ciencias, Bogotá, v. 6, n. 1, out. 1998.

DURBIN, G.; MORRIS, S.; WILKINSON, S. A teacher's guide to learning from objects. London: English Heritage, 1990.

FENSHAM, P. School science and public understand of science. International Journal of Science Education, London, v. 21, n. 7, p. 755-763, 1999.

GANGLIARDI, R.; GIORDAN, A. La historia de las ciencias: una herramienta para la enseñanza. Enseñanza de las Ciencias, Barcelona, v. 4, n. 3, p. 253-258, 1986.

GIL, F. B. Museus de ciência: preparação do futuro, memória do passado. Colóquio/Ciências: revista de Cultura Científica, Lisboa, n. 3, out. 1988.

GILBERT, J. Learning in museums: objects, models and text. Jem: Journal of Education in Museums, Somerset, n. 16, p. 19-21, 1995.

GOHN, M. da G. Educação não-formal e cultura política: impacto sobre o associativismo do terceiro setor. São Paulo: Cortez, 1999.

HEIN, G. E. The constructivist museum. Jem: Journal of Education in Museums, Somerset, n. 16, 1995.

HOOPER-GREENHILL, E. Los museos y sus visitantes. Espanha: Ediciones Trea, 1998.

MATTHEWS, M. R. Historia, filosofia y enseñanza de las ciencias: la aproximación actual. Historia y epistemologia de las ciencias. Enseñanza de las Ciencias, Barcelona, v. 12, n. 2, p. 255-277, 1994.

MILLER, J. D. Scientific literacy: a conceptual \& empirical review. Daedalus, Cambridge, v. 112, n. 2, 1983 .

PEDRINACI, E. La historia de la geología como herramienta didáctica. Enseñanza de las Ciencias de la Tierra, Cordoba, v. 2.2/2.3, p. 332-339, 1994.

SALVADOR, C. C. Aprendizagem escolar e construção do conhecimento. Porto Alegre: Artes Médicas, 1994. 
VALENTE, M. E. A.; MARANDINO, M. The combination of traditional and interactive objects in science museums. Museum education and new museology. Education, n. 17, p. 30-37, 2003.

VAN-PRÄET, M. A educação no museu, divulgar "saberes verdadeiros" com "coisas falsas"? In: GOUVÊA, G.; MARANDINO, M.; LEAL, M. C. (Org.). Educação e museu: a construção do caráter educativo dos museus de ciências. Rio de Janeiro: Faperj, 2002. p. 47-62. 